\title{
Comparison between Dexmedetomidine or Magnesium Sulfate as Adjuvants to Bupivacaine for Caudal Anesthesia in Pediatric Patients Undergoing Infraumbilical Surgeries
} Ahmed El-Saeed Abd El-Rahman Ali, Wesam Abd El-Galil Abu-Elwafa, Ghada Abdel-Gaber Rezk, Mariam Helal Rasmy*

Department of Anesthesia, ICU\& Pain management, Faculty of Medicine, Sohag University, Egypt Corresponding author: Mariam Helal Rasmy, Mobile: (+20)1202616877, E-Mail: mariamhelalrasmy@gmail.com

\begin{abstract}
Background: Caudal epidural anesthesia is a common technique providing intra and postoperative analgesia in pediatric infraumbilical surgical procedures.

Objectives: The aim of this study was to compare the effect of adding Dexmedetomidine or Magnesium Sulfate as an adjuvant to Bupivacaine for caudal anesthesia in pediatric infraumbilical surgeries.

Patients and Methods: This randomized controlled prospective study was done at Sohag University Hospital on sixty pediatric patients with American Society of Anesthesiologists (ASA) Classes I or II or III, weighted up to 20 $\mathrm{kg}$ scheduled for infraumbilical surgeries using caudal block in the period between January 2019 and January 2020. The included subjects were divided into three groups, twenty patients each: Group C (control), Group D (Dexmedetomidine group) and Group M (Magnesium group).

Results: In our study, the caudal block mainly used to relieve pain after Sevoflurane anesthesia with less incidence of emergence agitation. On comparing (Group D) and (Group M), Face, Legs, Activity, Cry, Consolability scale (FLACC) score was lower in (Group D: 0,1,1,2) than (Group M: 1,1,2,2) without significant difference at postoperative set times (30 minutes, $1,2,3$ hours), respectively. At the $6^{\text {th }}$ hour postoperatively, (Group M) patients achieved higher FLACC scores (3) compared with (Group D) patients (2.5) with statistically significant difference with $\mathrm{P}$ value of 0.05 . During the first 3 hours post-operative, there were higher sedation scores in (Group D: 4,4,3,3) and (Group M: 4,4,3,2.5) more than (Control group: 3,2.5,2,2) with highly statistical significant difference with (P value $<0.001)$ at $\left(30\right.$ minutes, $1 \mathrm{~h}, 2 \mathrm{~h}, 3$ hours), respectively. At the $6^{\text {th }}$ hour postoperatively, there were higher sedation scores with (Group D) (3) more than (Group M) (2) with highly statistical significant difference with (P value $<0.001)$.

Conclusion: Administration of Dexmedetomidine as adjuvant with Bupivacaine enhances caudal block, prolongs duration of postoperative analgesia, reduces postoperative EA and provides preferred postoperative sedation in pediatric patient undergoing infraumbilical surgeries with minimum adverse effects compared to Magnesium Sulfate as adjuvant.
\end{abstract}

Keywords: Dexmedetomidine, Magnesium Sulfate, Bupivacaine, Caudal anesthesia, Infraumbilical surgeries, postoperative agitation.

\section{INTRODUCTION}

Various multimodal techniques have been used for postoperative pain relief in children undergoing surgical procedures. These include both systemic and regional analgesia. Of the regional blocks, Caudal epidural analgesia is one of the most commonly performed technique in the pediatric anesthesia. It is a reliable and safe method that can be used in patients undergoing lower abdominal and lower limb surgeries ${ }^{(\mathbf{1})}$.

Many anesthetic agents have been used for caudal analgesia in pediatric patients, examples: Lignocaine and Bupivacaine being most common (2). Bupivacaine has been in clinical use for more than 25 years and is widely used for pediatric caudal epidural analgesia because of its preferential sensory than motor blocks ${ }^{(3)}$.

Unfortunately, the main disadvantage of caudal anesthesia depending on local anesthetics only is its relatively short duration of analgesia ${ }^{(4)}$. Prolongation of caudal analgesia using a "single-shot" technique has been achieved by the addition of various adjuvant such as opioids, ketamine, clonidine ${ }^{(5)}$.

The use of adjuvants, such as opioids, such as fentanyl and morphine, which have traditionally been used as adjuvants to epidural local anesthetics, are associated with side effects of pruritus, urinary retention, nausea and vomiting, and respiratory depression $^{(6)}$.

There is an increasing interest to study magnesium and dexmedetomidine analgesic effects. Many studies suggested that epidurally administered magnesium as an adjuvant to local anesthetics could reduce the postoperative pain in adults. But few studies are available about its use as an adjuvant in caudal block for such purpose ${ }^{(7)}$.

Dexmedetomidine, which is a highly selective $\alpha$ 2 adrenergic agonist with sedative and analgesic properties, has recently been used as an adjuvant to general and regional anesthesia in both adults and children $^{(\mathbf{8 , 9})}$. As of yet, dexmedetomidine has not been 
approved for use in the pediatric population in any country ${ }^{(10)}$.

The aim of this study was to compare the effect of adding Dexmedetomidine or Magnesium Sulfate as an adjuvant to Bupivacaine for caudal anesthesia in pediatric infraumbilical surgeries as regard onset and duration of the block as $1^{\text {st }}$ outcome, their effects on hemodynamics, recovery time, postoperative sedation, agitation and occurrence of complications as $2^{\text {nd }}$ outcome.

\section{PATIENTS AND METHODS}

This randomized controlled double blinded prospective study included a total of sixty pediatric patients with (ASA) Classes I or II or III, weighted up to $20 \mathrm{~kg}$ scheduled for infraumbilical surgeries using caudal block, attending at Sohag University Hospital. This study was conducted between January 2019 and January 2020.

\section{Ethical approval:}

Approval of the Ethical Research Committee of Sohag university was obtained.Written informed consent was taken from the parents of all patients participating in this work. All patients could refuse or withdraw from the research at any time without affecting the medical service provided.

The included subjects were divided into three groups, twenty patients each; Group C (control) patients received caudal injection of a mixture of Bupivacaine $(0.25 \%)+(0.9 \%)$ normal saline with a total volume of $(1 \mathrm{mg} / \mathrm{kg}$ ), Group D (Dexmedetomidine group) patients received caudal injection of a mixture of Bupivacaine $(0.25 \%)+$ Dexmedetomidine $(1 \mu \mathrm{g} / \mathrm{kg})$ with a total volume of $(1 \mathrm{mg} / \mathrm{kg}$ ) and Group M (Magnesium group): patients received caudal injection of a mixture of Bupivacaine $(0.25 \%)$ + Magnesium Sulfate $(50 \mathrm{mg}$ ) with a total volume of $(1 \mathrm{mg} / \mathrm{kg})$.

\section{Inclusion criteria:}

Pediatric patients, weighted up to $20 \mathrm{~kg}$, (ASA) Classes I \&II\&III and infraumbilical surgeries.

\section{Exclusion criteria:}

Patient's family refusal, patients weighted more than $20 \mathrm{~kg}$, (ASA) Class IV, coagulation disorders, preexisting neurological or spinal diseases, congenital malformations of the back, allergy to any drug used in the study and infection and skin lesions at puncture's site.

\section{Preparation of patients:}

All patients underwent a pre-anesthetic check-up, pre-operative investigations included complete blood count, coagulation profile, renal function tests, blood grouping and proper assessment of the airway.
- Fasting time: 2 hours of preoperative fasting for clear fluids, 4 hours of fasting for breast milk, and 6 hours of fasting for solids ${ }^{(\mathbf{1 1})}$.

- Monitoring: Once the patient was in the operating room, the standard monitors included pulse oximetry, electrocardiogram, pericardial stethoscope and noninvasive blood pressure was applied .

- Induction of anesthesia: Standard general anesthesia technique was performed for all patients using induction by face mask with sevoflurane MAC (6-8) inhalation. 24/22-gauge cannula was inserted. (I.V) Fluids were warmed and given. I-gel was inserted and anesthesia maintained by Sevoflurane MAC (1-3) inhalation by spontaneous ventilation.

Intravenous fluids: They were divided into:

\section{Maintenance:}

- Total maintenance requirement $(\mathrm{ml} / \mathrm{h})=1^{\text {st }} 10 \mathrm{~kg} \mathrm{x} 4$ $\mathrm{ml} / \mathrm{kg} / \mathrm{h} .+2^{\text {nd }} 10 \mathrm{~kg} \times 2 \mathrm{ml} / \mathrm{kg} / \mathrm{h} .+3^{\text {rd }} 10 \mathrm{~kg} \times 1$ $\mathrm{ml} / \mathrm{kg} / \mathrm{h}$.

- Type offluids:-5\% dextrose in $1 / 4$ or $1 / 2$ NS .

Deficit:

- It was calculated as follow = maintenance amount $/ \mathrm{hr}$ Xpreoperative fasting hours.

- It was given as follow: $50 \%$ in the $1^{\text {sth }}$ r/ of surgery. $\& 25 \%$ in the $2^{\text {nd }}$ and $3^{\text {rd } h r . s ~ o f ~ s u r g e r y . ~}$

- Type of fluids:-isotonic crystalloid.

\section{Replacement requirements:}

- $1 \mathrm{ml}$ colloid or $3 \mathrm{ml}$ lactated ringer for every $1 \mathrm{ml}$ blood lost.

- $3^{\text {rd }}$ space loss was replaced by $2-4 \mathrm{ml} / \mathrm{kg} / \mathrm{hr}$.

\section{Caudal block:}

The caudal anesthesia was been performed anatomically in the sacral portion of the epidural space using 22-gauge 3-cm, sterile, disposable needle. Patient's position was lateral (fetal) where the legs, knees, neck were flexed. Under complete aseptic condition, Entry point of the needle was identified by an anesthesiologist's finger of the non- dominant hand as a triangular depression between the 2 sacral cornua above the coccyx below. The needle was inserted perpendicularly to the skin until the sacrococcygeal membrane was penetrated (felt as a slight increase in resistance), then the needle was slightly withdrawn and lowered from 90 degrees to 45 degrees to the surface of the skin and advanced through the sacrococcygeal membrane. With sensation of loss of resistance, the needle was lowered parallel to the skin and advanced an additional $1-2 \mathrm{~cm}$ ensuring penetration into the caudal epidural space ${ }^{(\mathbf{1 2})}$.

Proper needle position was confirmed by: Injection of 2-3 $\mathrm{ml}$ of saline (the swoosh test) --- If the needle was in the epidural space, the saline's sound (swoosh) was heard by a stethoscope. 
Skin crepitus or elevation was palpated if the needle was not in the proper site. An aspiration test -with a gentle aspiration, If CSF or blood was aspirated, the caudal block was cancelled to avoid intravascular or intrathecal injection ${ }^{(\mathbf{1 2})}$.

After confirmation of the needle position, the local anesthetic dose (Bupivacaine) was injected as a single shot in form of one of the previous three groups. The patients were repositioned for surgery and the surgical procedure started after caudal block. At the end of the surgery, the volatile anesthesia was stopped. Patients' IGel was removed when adequate spontaneous ventilation established and then patients were transferred to the recovery room ${ }^{(\mathbf{1 2})}$.

The block was considered failed if the heart rate (HR) or mean arterial blood pressure (MAP) change was $>20 \%$ from the baseline and that patient was excluded from the study and intravenous (I.V) Fentanyl $(1 \mu \mathrm{g} / \mathrm{kg})$ was given to provide the analgesia. Bradycardia (if heart rate $[\mathrm{HR}]$ was $<20 \%$ from the baseline) \& Hypotension (if mean arterial blood pressure [MAP] was $<20 \%$ of baseline) were recorded and treated ${ }^{(12)}$.
Preparation of the injected drug:

- Volume: The volume was estimated according to Armitage ${ }^{(13)}$ :

- $(0.5 \mathrm{ml} / \mathrm{kg})$ below symphysis pubis.

- $\quad(0.75 \mathrm{ml} / \mathrm{kg})$ at level of symphysis pubis.

- $\quad(1 \mathrm{ml} / \mathrm{kg})$ up to symphysis pubis.

- Anesthetic agent: Bupivacaine $0.25 \%$ was prepared by diluting $0.5 \%$ bupivacaine with normal saline in the ratio of 1:1.

- Adjuvants: Dexmedetomidine in a dose of (1 $\mathrm{mic} / \mathrm{kg}$ ) and magnesium sulfate in a dose of $(50 \mathrm{mg})$.

\section{Statistical analysis}

Statistical analysis was carried out for numerical data using mean, $\mathrm{SD}$, and minimum and maximum of the range, whereas for categorical data number and percentage used. Analyses performed for quantitative variables using the one-way ANOVA test for parametric data between the two groups and using post-hoc analysis for two groups. Paired sample t-test used for parametric data between two variables in each group. The $\chi^{2}$-test used for qualitative data between groups. The level of significance at $\mathrm{P}$ value less than 0.05 .

\section{RESULTS}

Table (1): Demographic characteristics.

\begin{tabular}{|l|l|l|l|l||}
\hline Demographic variable & \multicolumn{1}{|c|}{$\begin{array}{c}\text { Group C } \\
\mathbf{N = 2 0}\end{array}$} & $\begin{array}{c}\text { Group D } \\
\mathbf{N = 2 0}\end{array}$ & $\begin{array}{c}\text { Group M } \\
\text { N=20 }\end{array}$ & P value \\
\hline Age, years (mean \pm SD) & $29.2 \pm 20.59$ & $35.7 \pm 19.08$ & $37.95 \pm 19.38$ & $0.352(\mathrm{NS})$ \\
\hline $\begin{array}{l}\text { Weight, kg } \\
(\mathbf{m e a n} \pm \text { SD) }\end{array}$ & $12.725 \pm 4.92$ & $14.8 \pm 3.73$ & $15.25 \pm 3.85$ & $0.138(\mathrm{NS})$ \\
\hline Gender (male/female) & $17 / 3$ & $19 / 1$ & $19 / 1$ & $0.227(\mathrm{NS})$ \\
\hline $\begin{array}{l}\text { Duration of surgery, minutes } \\
\text { (mean } \pm \text { SD) }\end{array}$ & $54 \pm 25$ & $63.75 \pm 24.2$ & $63 \pm 31.76$ & $0.457(\mathrm{NS})$ \\
\hline
\end{tabular}

Data are presented as Mean \pm standard deviation.

$P$ value $<0.05$ is considered significant

N.S: nonsignificant $\mathrm{P}$ value.

Age, sex, weight and the operative duration were compared between the three groups and presented in table (1) as Mean \pm Standard deviation (Mean \pm SD). In (Group C) there was 17 males $(85 \%)$ and 3 females $(15 \%)$, in (Group D) there was 19 males (95\%) and 1 female (5\%), also in (Group M) there was 19 males (95\%) and 1 female $(5 \%)$.

There was no statistically significant difference between the three groups as regard age, sex, weight or the operative duration .

\section{Haemodynamics monitoring:}

As regard heart rate monitoring (Figure 1), we found: There was a statistically significant difference regarding heart rate between (Group D) (109-102.6-98.58-94.7693.66-87.33-103.65-106.9-108.15-108.6-111.8-115.6127.85) and (Group C) (124.7-122-117-119.33-115107.33-113.9-117.9-122.3-127.75-132.2-141.6-131.2) from the $20^{\text {th }}$ minutes and every 15 minutes intraoperative till 12 hours postoperative,respectively. It was lower in (Group D). There was no significant difference in heart rate measurements between (Group M) (117.65-114.05-111.2-111.2-108.25-99.2-106.05111.5-114.8-119.15-123.9-130.8) and (Group C) (124.7-122-117-119.33-115-107.33-113.9-117.9$122.3-127.75-132.2-141.6-131.2)$ from the $20^{\text {th }}$ minutes and every 15 minutes intraoperative till 12 hours postoperative,respectively. It was lower in (Group M). There was no significant difference between (Group M) and (Group D), although mean heart rate measurements in (Group D) was lower than (Group M) but no 
significant difference. As regard mean blood pressure monitoring (Figure 2), we found there was no significant difference between three study groups during the intraoperative and postoperative periods. As regard respiratory rate monitoring (Figure 3 ), we found there was no significant difference between three study groups during the intraoperative and postoperative periods. As regard oxygen saturation monitoring (Figure 4), we found there was no significant difference between three study groups during the intraoperative and postoperative periods.

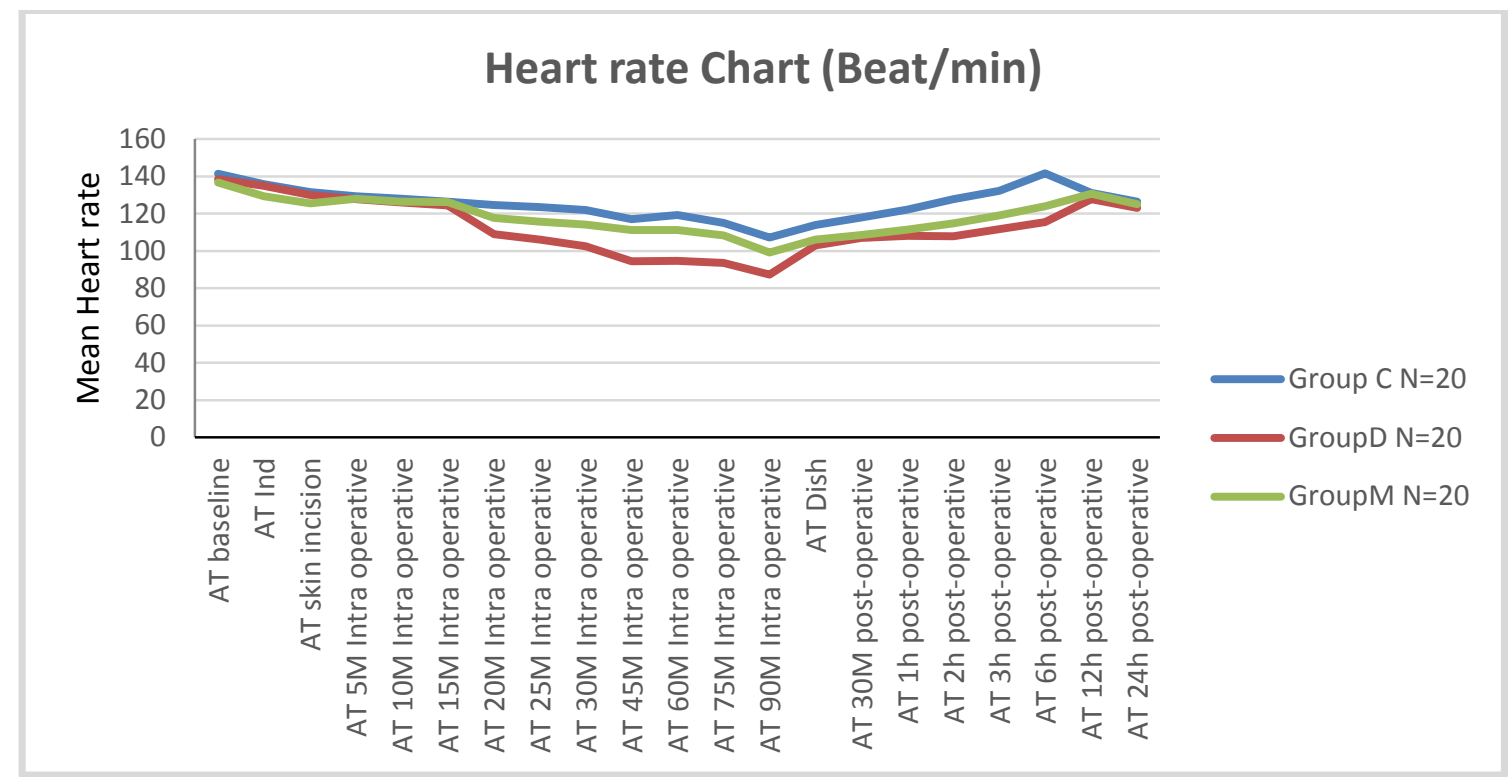

FIG (1): Means of heart rate.

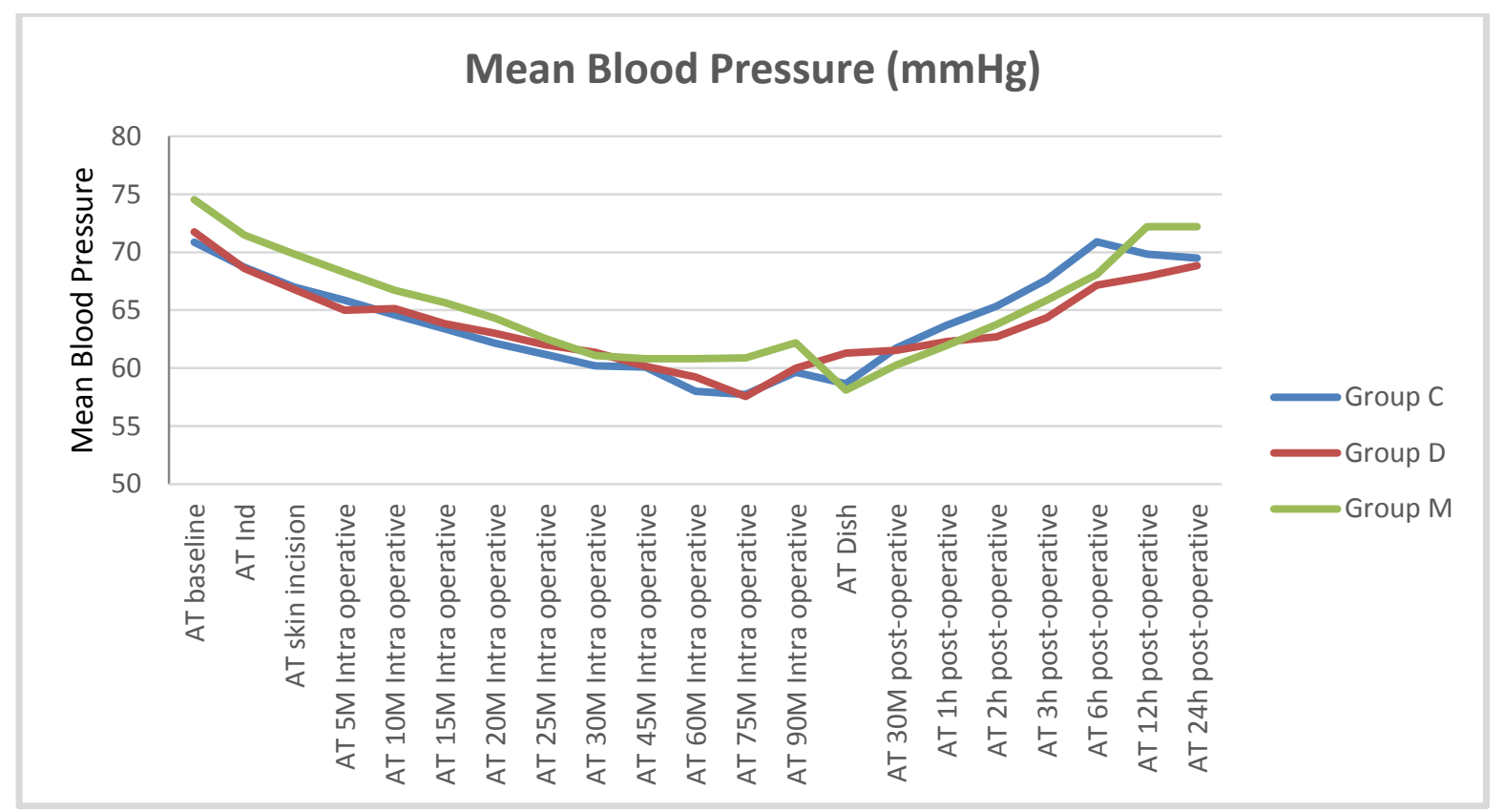

FIG (2): Means of arterial blood pressure. 


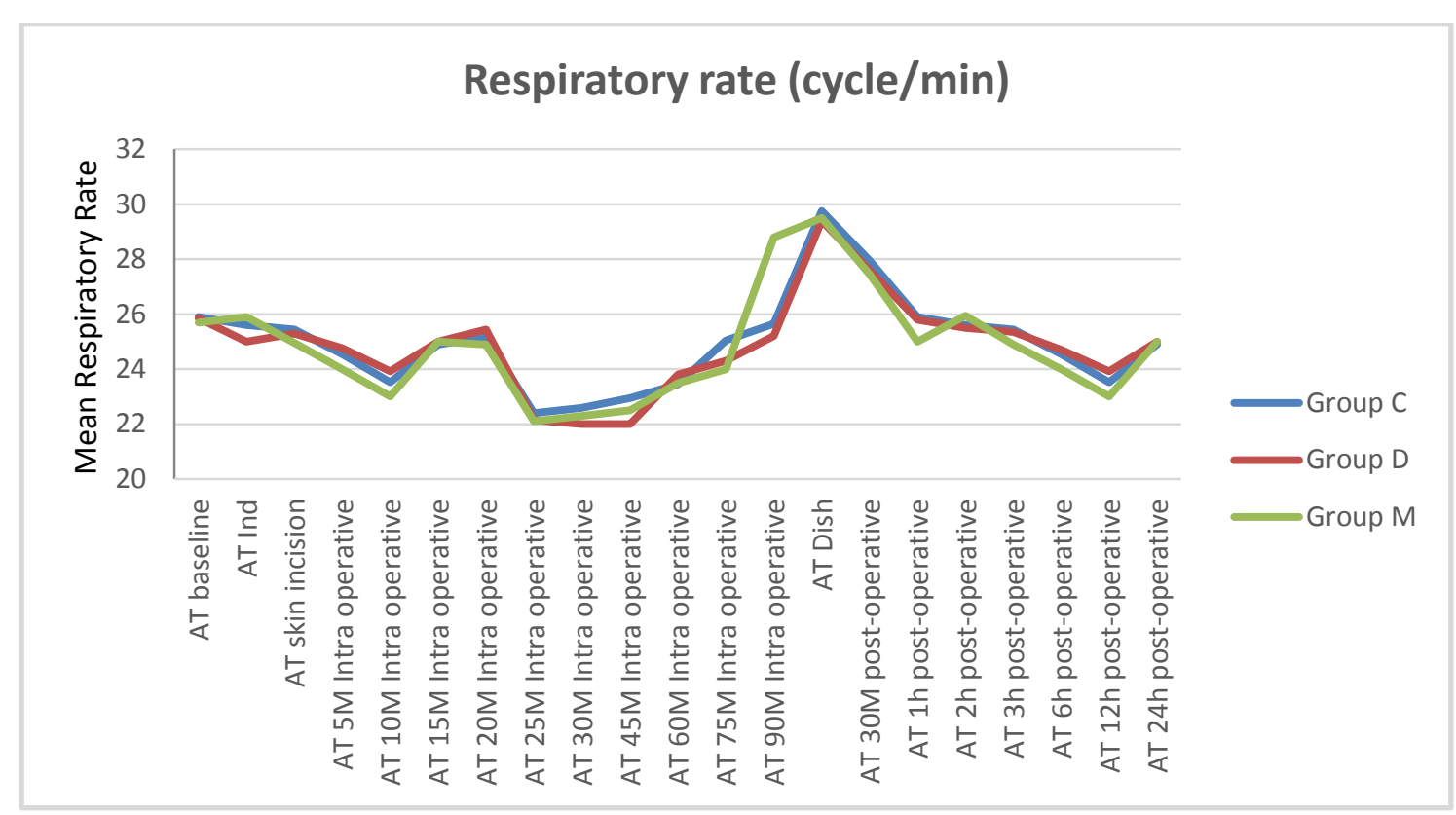

FIG (3): Means of respiratory rate.

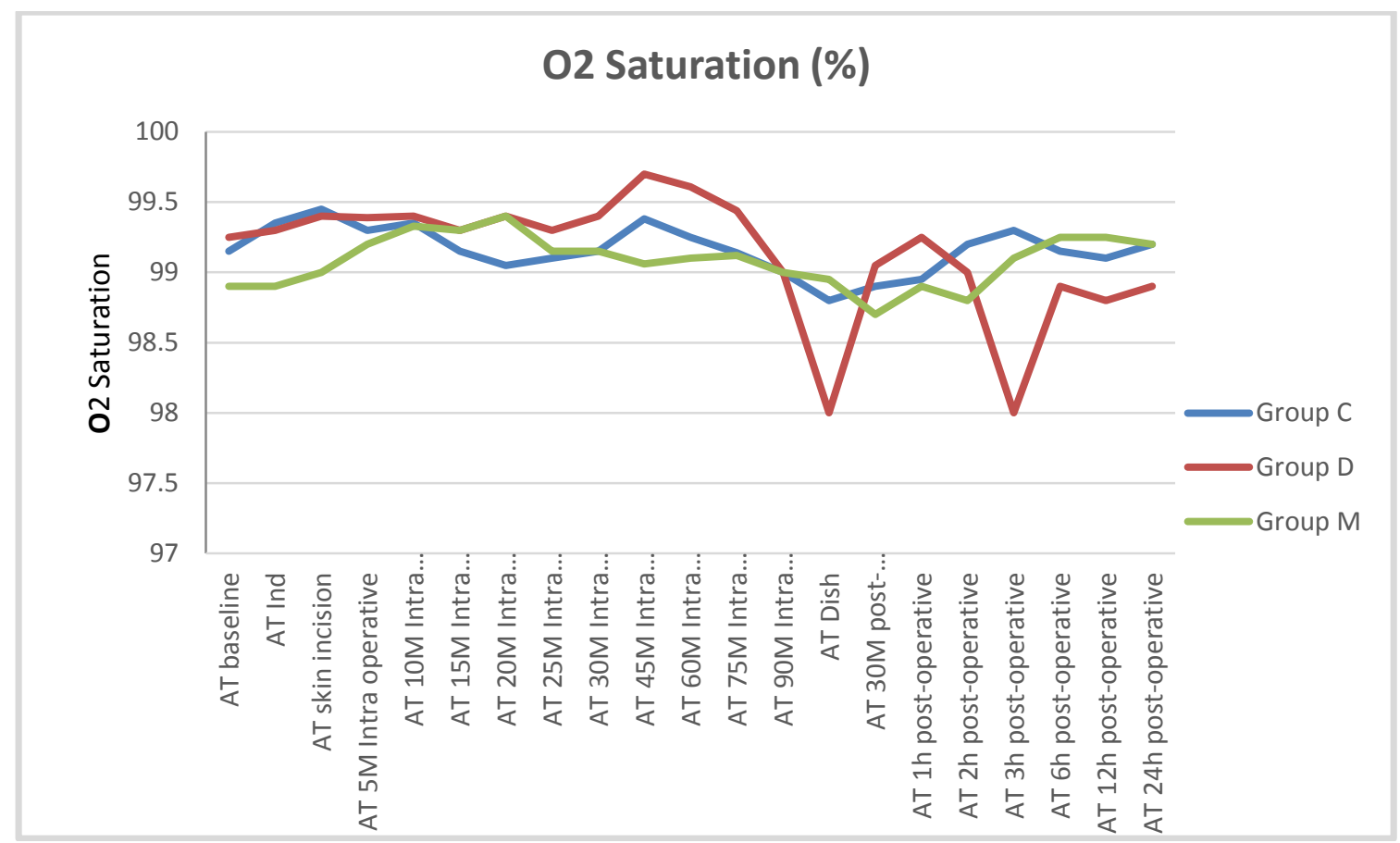

FIG (4): Means of oxygen saturation.

Table (2): Aldrete score.

\begin{tabular}{|l|l|l|l|l|l|l|l||}
\hline & $\begin{array}{l}\text { Group C } \\
\text { N=20 }\end{array}$ & $\begin{array}{l}\text { Group D } \\
\mathbf{N = 2 0}\end{array}$ & $\begin{array}{l}\text { Group } \\
\mathbf{M} \\
\text { N=20 }\end{array}$ & P & P1 & P2 & P3 \\
\hline Aldrete score & $9.5(9-12)$ & $9(9-12)$ & $9(9-12)$ & $0.79(\mathrm{NS})$ & 1.00 & 1.00 & 1.00 \\
\hline Time & $7.6 \pm 2.3$ & $7.4 \pm 1.84$ & $7.55 \pm 1.9$ & $0.95(\mathrm{NS})$ & 1.00 & 1.00 & 1.00 \\
\hline
\end{tabular}

Data are presented as mean \pm standard deviation, and median (range).

P compared the 3 groups, p1 compared group (1) \& (2),

P2 compared group (1) \& (3), p3 compared group (2) \& (3) Significant at p<0.05.

There was no significant difference on comparing the alderte score of discharge and time taken to be discharged from the operative room of the three groups (time $\mathrm{P}$ value $=0.95)($ score $\mathrm{P}$ value $=0.79)($ Table 2$)$. 
Table (3): FLACC score.

\begin{tabular}{||l|l|l|l|l|l|l|l||}
\hline Time & $\begin{array}{l}\text { Group C } \\
\mathbf{N = 2 0}\end{array}$ & $\begin{array}{l}\text { Group D } \\
\mathbf{N = 2 0}\end{array}$ & $\begin{array}{l}\text { Group M } \\
\mathbf{N = 2 0}\end{array}$ & P & P1 & P2 & P3 \\
\hline AT 30M post-operative & $1(0-2)$ & $0(0-1)$ & $1(0-2)$ & $0.01(\mathrm{~S})$ & 0.01 & 0.017 & 0.82 \\
\hline AT 1h post-operative & $2(1-3)$ & $1(0-1)$ & $1(0-2)$ & $0.00(\mathrm{HS})$ & 0.00 & 0.04 & 0.06 \\
\hline AT 2h post-operative & $3(2-3)$ & $1(0-2)$ & $2(0-3)$ & $0.00(\mathrm{HS})$ & 0.00 & 0.00 & 0.11 \\
\hline AT 3h post-operative & $3(2-3)$ & $2(0-1)$ & $2(1-3)$ & $0.00(\mathrm{HS})$ & 0.00 & 0.02 & 0.06 \\
\hline AT 6h post-operative & $5(4-6)$ & $2.5(1-3)$ & $3(2-3)$ & $0.00(\mathrm{HS})$ & 0.00 & 0.00 & 0.05 \\
\hline AT 12h post-operative & $3(1-4)$ & $3(2-3)$ & $3.5(0-4)$ & $1.00(\mathrm{NS})$ & .90 & 1.00 & 1.00 \\
\hline AT 24h post-operative & $3(2-5)$ & $3(1-4)$ & $3(2-5)$ & $0.76(\mathrm{NS})$ & 1.00 & 1.00 & 1.00 \\
\hline
\end{tabular}

Data are presented as median (range).

P compared the 3 groups, p1 compared group (1) \& (2),

P2 compared group (1) \& (3), p3 compared group (2) \& (3) Significant at p<0.05

During the first 12 hours postoperative, FLACC score was lower in (Group D) than (Group C), also it was lower in (Group M) than (Group C) with statistically significant differences. On comparing (Group D) and (Group M), FLACC score was lower in (Group D: 0,1,1,2) than (Group M: 1,1,2,2) without significant difference at postoperative set times (30 minutes, 1,2,3 hours), respectively. At the $6^{\text {th }}$ hour postoperatively, (Group M) patients achieved higher FLACC scores (3) compared with (Group D) patients (2.5) with statistically significant difference with P value of 0.05 . At the $12^{\text {th }}$ hour and at the $24^{\text {th }}$ hour postoperatively, all groups had higher pain scores without statistically significant difference between them(Table 3).

Table (4): Ramsay sedation score.

\begin{tabular}{|l|l|l|l|l|l|l|l||}
\hline Time & $\begin{array}{l}\text { Group C } \\
\mathbf{N = 2 0}\end{array}$ & $\begin{array}{l}\text { Group D } \\
\mathbf{N = 2 0}\end{array}$ & $\begin{array}{l}\text { Group M } \\
\mathbf{N = 2 0}\end{array}$ & P & P1 & P2 & P3 \\
\hline AT 30M post-operative & $3(3-4)$ & $4(3-5)$ & $4(3-5)$ & $0.00(\mathrm{HS})$ & 0.00 & 0.00 & 0.44 \\
\hline AT 1h post-operative & $2.5(2-3)$ & $4(2-4)$ & $4(2-4)$ & $0.00(\mathrm{HS})$ & 0.00 & 0.00 & 1.00 \\
\hline AT 2h post-operative & $2(2-3)$ & $3(2-4)$ & $3(2-3)$ & $0.00(\mathrm{HS})$ & 0.00 & 0.00 & 0.20 \\
\hline AT 3h post-operative & $2(2-2)$ & $3(2-3)$ & $2.5(2-3)$ & $0.00(\mathrm{HS})$ & 0.00 & 0.00 & 0.75 \\
\hline AT 6h post-operative & $2(2-3)$ & $3(2-3)$ & $2(2-3)$ & $0.00(\mathrm{HS})$ & 0.00 & 0.28 & 0.00 \\
\hline AT 12h post-operative & $2(0-2)$ & $2(1-2)$ & $2(1-2)$ & $0.74(\mathrm{NS})$ & 1.00 & 1.00 & 1.00 \\
\hline AT 24h post-operative & $2(2-2)$ & $2(2-2)$ & $2(0-2)$ & $0.37(\mathrm{NS})$ & 1.00 & 0.68 & 0.68 \\
\hline
\end{tabular}

Data are presented as median (range).

P compared the 3 groups, p1 compared group (1) \& (2),

P2 compared group (1) \& (3), p3 compared group (2) \& (3) Significant at $p<0.05$.

During the first 3 hours post-operative, there were higher sedation scores in (Group D: 4,4,3,3) and (Group M: 4,4,3,2.5) more than (Control group: 3,2.5,2,2) with highly statistical significant difference (P value $<0.001)$ at (30 minutes, $1 \mathrm{~h}, 2 \mathrm{~h}, 3$ hours), respectively. At the $6^{\text {th }}$ hour postoperatively, there were higher sedation scores with (Group D) (3) more than (Group M) (2) with highly statistical significant difference (P value $<0.001)$. At the $12^{\text {th }}$ hour and at $24^{\text {th }}$ hour postoperatively, all groups had less sedation scores without statistically significant difference between them(Table 4). 


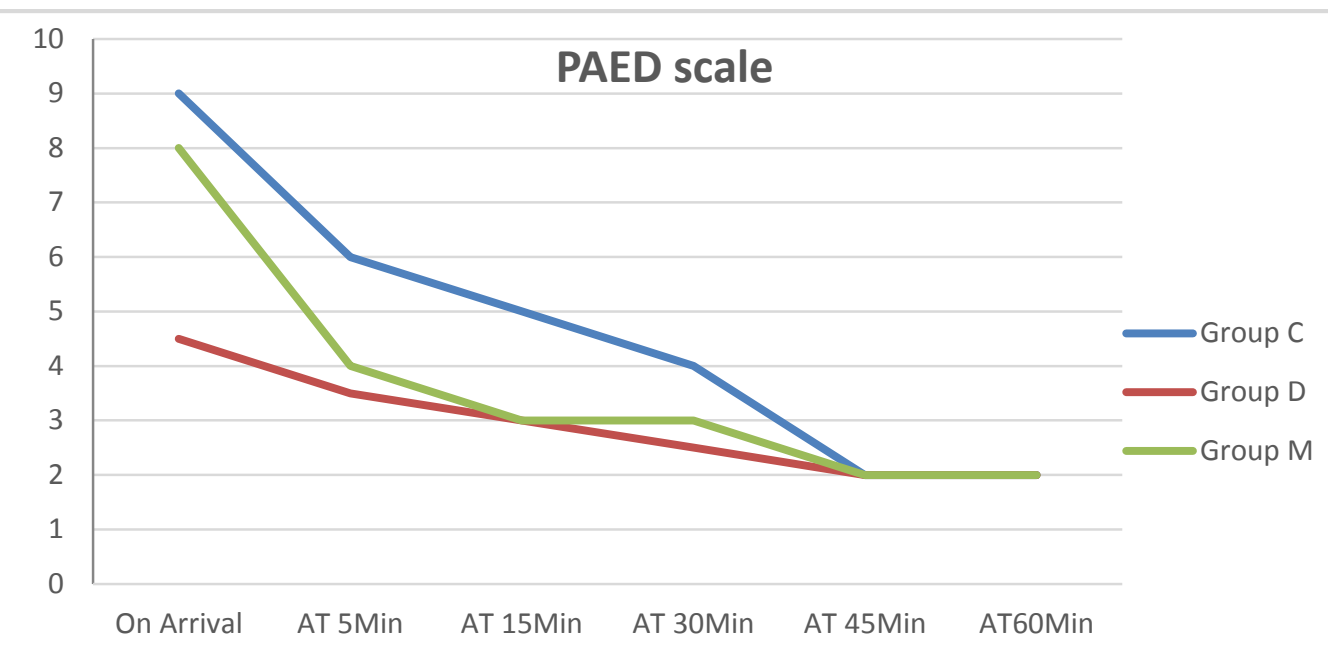

FIG (5): Median of PAED score.

On comparing (Group D) and (Group M) with (Group C), there were highly statistical significant lower PAED scores $(3.5,3,3)$ and $(4,3,3)$ than (Group C: $6,5,4)$ at $(5,15,30$ minutes) postoperative, respectively with $\mathrm{P}$ value $<0.001$. later on, there is no significant difference between all groups (Figure 5).

Table (5): Correlation between - FLACC score\& Ramsy score and PAED scale.

\begin{tabular}{|l|c|c|}
\hline & $\begin{array}{l}\text { CORRELATION } \\
\text { CO-EFFICIENT( R ) }\end{array}$ & P VALUE \\
\hline FLACC score\&Ramsy score(AT 30Min) & -0.166 & 0.206 \\
\hline FLACC score\&Ramsy score(AT 60Min) & -0.294 & $0.023^{*}$ \\
\hline FLACC score\& PAED scale(AT 30Min) & 0.192 & 0.142 \\
\hline FLACC score\& PAED scale(AT 60Min) & 0.235 & 0.071 \\
\hline PAED scale \&Ramsy score(AT 30Min) & -0.47 & $0.00^{* *}$ \\
\hline PAED scale \&Ramsy score(AT 60Min) & -.312 & $0.028^{*}$ \\
\hline
\end{tabular}

**. Correlation is highly significant at the 0.01 level (2-tailed).

*. Correlation is significant at the 0.05 level (2-tailed).

At 30 minutes postoperative, there was -ve correlation between pain and sedation without statistically significant difference $(\mathrm{P}=0.206)$. There was less $+\mathrm{ve}$ correlation between pain and agitation without statistically significant difference $(\mathrm{P}=0.142)$. There was -ve correlation between sedation and agitation with highly statistically significant difference $(\mathrm{P}<0.001)$.

At 60 minutes postoperative, there was -ve correlation between pain and sedation with statistically significant difference $(\mathrm{P}=0.023)$. There was less $+\mathrm{ve}$ correlation between pain and agitation without statistically significant difference $(\mathrm{P}=0.071)$. There was -ve correlation between sedation and agitation with statistically significant difference $(\mathrm{P}=0.028)($ Table 5).

Table (6): Complications frequency and percentage.

\begin{tabular}{|l|l|l|l|l|l|l|}
\hline \hline & \multicolumn{2}{|c|}{ Group C (N=20) } & \multicolumn{2}{c|}{ Group D (N=20) } & \multicolumn{2}{c|}{ Group M (N=20) } \\
\hline & $\mathbf{N}$ & $\mathbf{\%}$ & $\mathbf{N}$ & $\mathbf{\%}$ & $\mathbf{N}$ & $\mathbf{\%}$ \\
\hline Bradycardia & 0 & 0 & 1 & $5 \%$ & 0 & 0 \\
\hline Hypotension & 0 & 0 & 0 & 0 & 0 & 0 \\
\hline Hypoxia & 0 & 0 & 0 & 0 & 0 & 0 \\
\hline Vomiting & 0 & 0 & 2 & $10 \%$ & 1 & $5 \%$ \\
\hline Prolonged motor power & 0 & 0 & 0 & 0 & 0 & 0 \\
\hline DCL & 0 & 0 & 0 & 0 & 0 & 0 \\
\hline
\end{tabular}

As regard complications, monitoring of the following: vomiting bradycardia hypotension disturbed conscious level or motor affection. Only one patient developed vomitting in (Group M) $(5 \%)$ postoperative compared to two patients in (Group D) (10\%) and no patients in (Group C) (0\%). also one patient in (Group D) developed bradycardia (5\%) compared to no patients in (Group C) $(0 \%)$ or (Group M) $(0 \%)$ (Table 6). 


\section{DISCUSSION}

As regard demographic data in the current study, there were no statistically significant differences between the three groups including age, weight, sex and the operative duration.

As regard duration of analgesia (from the onset of block up to 1st analgesic requirement), we noticed highly significant longer duration of the caudal block in (Group D) (487.8 $\pm 48.16 \mathrm{~min}$ ) compared to (Group C) $(294.8 \pm 43.66 \mathrm{~min})$. Also, there was highly significant difference between (Group M) (476.45 $\pm 41.79 \mathrm{~min})$ and (Group C) (294.8 $\pm 43.66 \mathrm{~min})$. On comparison of the duration of the block between (Group M) and (Group D), there was no statistically significant difference between the two groups but still longer duration with (Group D) than (Group M). 1st consumption of analgesia during postoperative 24 hours were $(228.75 \pm 57.76 \mathrm{mg}), \quad(222.75 \pm 56.04 \mathrm{mg})$ and (190.875 $\pm 73.9 \mathrm{mg})$ in (Group M), (Group D) and (Group $\mathrm{C})$, respectively with (P value of 0.14 ).

Our results came in agreement with the results of Gupta and Sharma study ${ }^{(14)}$, which included 60 children (1-8 years), scheduled for infraumbilical surgeries, who were randomly assigned into two groups: (Group Ropivacaine with Tramadol) (RT) received Ropivacaine $(0.25 \%)(1 \mathrm{ml} / \mathrm{kg})+$ Tramadol $(2 \mathrm{mg} / \mathrm{kg})$ and (Group Ropivacaine with Dexmedetomidine) (RD) received Ropivacaine

$(0.25 \%)$ $(1 \mathrm{~mL} / \mathrm{kg})+$ Dexmedetomidine $(2 \mu \mathrm{g} / \mathrm{kg})$. They showed the duration of analgesia was highly significant prolonged with (Group RD) $(780.29 \pm 71.21 \mathrm{~min})$ more than (Group RT) $(654.20 \pm 78.38 \mathrm{~min})$ with $(P<$ 0.0001).

Our results are in agreement also with Sridhar $\boldsymbol{e t}$

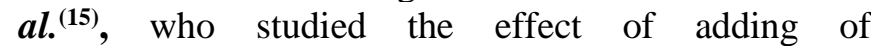
Dexmedetomidine (1 $\mu \mathrm{g} / \mathrm{kg})$, Dexamethasone $(0.1$ $\mathrm{mg} / \mathrm{kg}$ ) or Magnesium (50mg) as adjuvant to caudal Ropivacaine $(0.2 \%)(0.5 \mathrm{ml} / \mathrm{kg})$ in pediatric patients, scheduled for infraumbilical surgeries. They found the adding of Dexmedetomidine or Magnesium prolonged the duration of postoperative analgesia $(406.2 \pm 45.5$ min) $\&(325.0 \pm 45.8 \mathrm{~min})$, respectively as compared to Control Group ( $285.9 \pm 52.7 \mathrm{~min})$ with a statistically significant difference $(P<0.001)$.

In agreement with our study for using Magnesium Sulfate as an adjuvant to caudal block, Kim et al..$^{(\mathbf{1 6})}$, applied their study on 80 children, aged 2-6 years undergoing inguinal herniorrhaphy to detect the effects of adding Magnesium (50mg) as an adjuvant for caudal Ropivacaine $(1.5 \mathrm{mg} / \mathrm{ml})(1 \mathrm{ml} / \mathrm{kg})$. They classified patients into two groups: (Group R) received Ropivacaine alone and (Group RM) received the same dose of Ropivacaine mixed with Magnesium. They found that addition of Magnesium to Ropivacaine prolonged the postoperative analgesia in (Group RM) with median (485(345-650) minutes) more longer than in (Group R) with median (390(360-660) minutes $).(\mathrm{P}=0.740)$

As regard hemodynamics monitoring perioperatively, the current study revealed that there was a statistically significant difference regarding heart rate between (Group D) and (Group C) at 20 minutes intraoperative till 12 hours postoperative, It was lower in (Group D). There was no statistically significant difference between (Group M) and (Group C) but still lower than (Group C) at the same times.

Also, regarding Mean blood pressure, there was no significant difference between the two study groups and the control group intra and postoperative. Furthermore, there was no significant difference regarding respiratory rate and oxygen saturation between the two study groups and the control group at observation times intraoperative and also till 24 hours postoperative.

Our results came in agreement with that of Park $\boldsymbol{e t}$ al. ${ }^{(17)}$, who compared between Dexmedetomidine $(1 \mu \mathrm{g} / \mathrm{kg})$ and Fentanyl $(1 \mu \mathrm{g} / \mathrm{kg})$ as an adjuvant to Ropivacaine $(0.2 \%)(0.2 \mathrm{ml} / \mathrm{kg})$. This study included 60 children, aged 3-12 years old, scheduled for orthopedic surgery of the lower extremities and lumbar epidural patient-controlled analgesia (PCA). They showed that Dexmedetomidine group patients developed a gradual decrease as regard heart rate measurements with no statistically significant differences. There was no significant difference as regard Mean BLP measurements in both groups.

Also, in agreement with our study, Khaled $\boldsymbol{e t}$

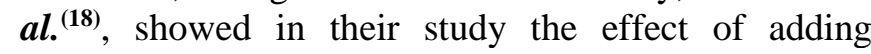
Dexmedetomidine $(1 \mu \mathrm{g} / \mathrm{kg})$ to caudal Bupivacaine $(0.25 \%)(1 \mathrm{~mL} / \mathrm{kg})$. Up to 30 minutes intraoperative, heart rate measurements showed a significant drop in (Bupivacaine-Dexmedetomidine) group more than in (Bupivacaine alone) group with $\mathrm{P}$ value $<0.001$. But, in contrast to our study, the intraoperative Mean BLP showed a significant drop in both study groups at the same set times with $P$ value $<0.001$.

In contrast to our study, the results of Sridhar et al. ${ }^{(15)}$, showed the effect of adding Dexmedetomidine $(1 \mu \mathrm{g} / \mathrm{kg})$, Dexamethasone $(0.1 \mathrm{mg} / \mathrm{kg})$ or Magnesium (50mg) as adjuvant to caudal Ropivacaine $(0.2 \%)$ $(0.5 \mathrm{ml} / \mathrm{kg})$ in pediatric patients undergoing infraumbilical surgeries. There was no statistical difference with the hemodynamic parameters between Dexmedetomidine and Bupivacaine groups. This might be explained by the use of a smaller volume of caudal injection in their study than our study $(0.5 \mathrm{ml} / \mathrm{kg})$ \& $(1 \mathrm{ml} / \mathrm{kg})$, respectively and/or the use of a different type of local anesthetic (Ropivacaine $0.2 \%$ ) unlike our study (Bupivacaine 0.25\%).

As regard the postoperative recovery time (using aldrete score), there was no significant 
difference between the three groups (Group D) (7.4 \pm 1.84$)$, (Group M) $(7.55 \pm 1.9)$ and (Group C) (7.6 \pm 2.3 ) with (P value of 0.79$)$.

Our results came in agreement with Mavuriet $\boldsymbol{a l} .{ }^{(19)}$, who used Dexmedetomidine $(1 \mu \mathrm{g} / \mathrm{kg})$ or Clonidine $(1 \mu \mathrm{g} / \mathrm{kg})$ with Ropivacaine $(0.2 \%)$ $(1.5 \mathrm{mg} / \mathrm{kg})$ in caudal analgesia on 78 children, aged 6 months-6 years, undergoing lower abdominal surgeries. The children were randomly allocated into two groups: (RC Group) and (RD Group). They revealed that the adding of Dexmedetomidine didn't cause any delay in recovery from general anesthesia.

Also, our study agreed with the results of Farraget al. ${ }^{(20)}$, in their study on pediatrics undergoing unilateral hernia repair/orchiopexy. 40 Patients were allocated into one of two groups received with caudal block: either (Group BM): Bupivacaine $(0.5 \mathrm{ml} / \mathrm{kg})(0.25 \%)+$ Magnesium $(50 \mathrm{mg})$ or (Group BK): Bupivacaine $(0.5 \mathrm{ml} / \mathrm{kg})(0.25 \%)+$ Ketamine $(0.5 \mathrm{mg} / \mathrm{kg})$. There was no significant difference as regard the recovery time between (Group BM) and (Group BK) with $($ mean \pm SD) of $(14.7 \pm 5.1) \&(13.6 \pm 4.2)$, respectively.

As regard postoperative pain assessment using FLACC score in our study, During the first 12 hours postoperative, FLACC score was lower in (Group D) than (Group C), also it was lower in (Group M) than (Group C) with statistically significant differences.

On comparing (Group D) and (Group M), FLACC score was lower in (Group D: $0,1,1,2$ ) than (Group M: $1,1,2,2)$ without significant difference at postoperative set times (30 minutes, 1,2,3 hours), respectively. At the $6^{\text {th }}$ hour postoperatively, (Group M) patients achieved higher FLACC scores (3) compared with (Group D) patients (2.5) with statistically significant difference with $\mathrm{P}$ value of 0.05 . At the $12^{\text {th }}$ hour and at the $24^{\text {th }}$ hour postoperatively, all groups had higher pain scores without statistically significant difference between them.

Our results are in agreement also with Tandale $\boldsymbol{e t}$ $\boldsymbol{a l} .^{(21)}$, in their study on efficacy and safety of Dexmedetomidine $(1 \mu / \mathrm{kg})$ as an adjuvant to caudal Levobupivacaine $(0.25 \%)(1 \mathrm{ml} / \mathrm{kg})$ for herniotomy and orchiopexy and $(0.5 \mathrm{ml} / \mathrm{kg})$ for circumcision in pediatric patients. They were randomly assigned in two groups, (Group L) with Levobupivacaine and (Group LD) with Levobupivacaine+dexmedetomidine $(1 \mu / \mathrm{kg})$. This study revealed that (Group LD) patients achieved highly statistical significant reduction in FLACC score compared to patients in (Group L) at (2,3,4 and 6 hours) postoperatively.

Also, it agreed with Goyal $\boldsymbol{e t} \boldsymbol{a l} .^{(22)}$, studied the use of Dexmedetomidine as an adjuvant to Bupivacaine in caudal analgesia in children. They showed that patients belonging to (Group B) achieved highly statistical significant lower FLACC scores throughout the initial 12 hours of postoperative period compared to control group with $(P<0.0001)$.

Furthermore, El-Hennawy et al. ${ }^{(23)}$, by adding Dexmedetomidine or Clonidine to Bupivacaine $(0.25 \%)$ $(1 \mathrm{ml} / \mathrm{kg})$ in caudal analgesia on 60 children in a form of three groups. (Group A) received Bupivacaine with Dexmedetomidine $(2 \mu \mathrm{g} / \mathrm{kg}$ ), (Group B) received Bupivacaine with Clonidine $(2 \mu \mathrm{g} / \mathrm{kg}$ ) and (Group C) received Bupivacaine alone. During the first 4 hours postoperative, there was statistically significant difference between the groups as regard FLACC score. Groups (A) and (B) achieved significantly lower FLACC scores compared with (Group C).

Also, Jilani et al. ${ }^{(24)}$, showed the effect of adding Magnesium Sulfate $(50 \mathrm{mg})$ on pediatric caudal Bupivacaine $(0.25 \%)(1 \mathrm{ml} / \mathrm{kg})$ on 60 children, ASA I and II, aged 1 year to 6 years, undergoing elective lower abdominal surgeries. They were randomized into one of two groups either received of Magnesium Sulfate (Group Mg) added to Bupivacaine or Bupivacaine alone in (Group C). (Group MG) experienced a highly statistical significant decrease in FLACC score compared to (Group C) at (30 minutes, after 120 minutes up to 6 hours), postoperatively with $\mathrm{P}$ value $<0.001$.

Our results also agreed with results of Askar $\boldsymbol{e t}$ $\boldsymbol{a l} .{ }^{(25)}$, who studied the effect of adding Magnesium Sulfate to pediatric caudal Bupivacaine on hemodynamics parameters and surgical stress. That revealed (Group $\mathrm{Mg}$ ) had lower FLACC scores than (Group C) at the first postoperative six hours with highly statistical significant difference with $\mathrm{P}$ value $<0.001$.

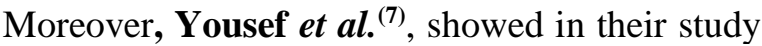
the enhancement of Ropivacaine $(0.15 \%)(1.5 \mathrm{~mL} / \mathrm{kg})$ caudal analgesia by using Magnesium $(50 \mathrm{mg}$ ) or Dexamethasone $(0.1 \mathrm{mg} / \mathrm{kg})$ in children undergoing inguinal hernia repair.Ropivacaine alone group (Group R) achieved significantly higher FLACC score (4.5) at the $4^{\text {th }}$ hour postoperatively. Magnesium group (Group RM) achieved significantly higher FLACC score (4) at the $8^{\text {th }}$ hour postoperatively.

Incontrast to our study, the study of Birbicer et al. ${ }^{(26)}$, by adding Magnesium (50 $\mathrm{mg})$ as adjuvant to Ropivacaine $(0.25 \%)(0.5 \mathrm{ml} / \mathrm{kg})$ in caudal anesthesia. This study was carried on 60 infants and children, aged 2-10 years, presented for elective minor surgery under general anesthesia. There was no statistically significant difference between the Group received (Ropivacaine) and Group received (Ropivacaine with Magnesium Sulfate) regarding CHEOPS and POPS pain scores with $P$ value $>0.05$. It might be explained by the use of a different type of local anesthetic (Ropivacaine 0.2\%) unlike our study (Bupivacaine $0.25 \%$ ) and/or the significant heterogeneity of the used pain scores (CHEOPS \&POPS scores) and FLACC score in their study and our study, respectively. 
Regarding postoperative sedation assessment in our study using Ramsay sedation score, During the first 3 hours post-operative, there were higher sedation scores in (Group D: 4,4,3,3) and (Group M: 4,4,3,2.5) more than (Control group: 3,2.5,2,2) with highly statistical significant difference with $(\mathrm{P}$ value $<0.001)$ at $(30$ minutes, $1 \mathrm{~h}, 2 \mathrm{~h}, 3$ hours), respectively.

At the $6^{\text {th }}$ hour postoperatively, there were higher sedation scores with (Group D) (3) more than (Group M) (2) with highly statistical significant difference with ( $\mathrm{P}$ value $<0.001$ ).

At the $12^{\text {th }}$ hour and at $24^{\text {th }}$ hour postoperatively, all groups had less sedation scores without statistically significant difference.

Our results came in agreement with the results of Khaled et al. ${ }^{(18)}$, who showed in their study the effect of adding of Dexmedetomidine $(1 \mu \mathrm{g} / \mathrm{kg})$ to caudal Bupivacaine $(0.25 \%)(1 \mathrm{~mL} / \mathrm{kg})$ on the sedation score. Their study was applied on 40 pediatric patients scheduled for major abdominal cancer surgeries. Both groups started with the same sedation score (3) then, decreased in both groups at the first 4 hours postoperative with higher score in (Group D). Up to 24 hours postoperative, the patients in both groups showed the same sedation scores (2).

Also, Anand et al. ${ }^{(27)}$, showed in their study the effects of adding of Dexmedetomidine $(1 \mu \mathrm{g} / \mathrm{kg})$ to caudal Ropivacaine $(0.25 \%)$ in pediatric lower abdominal surgeries. Sixty children were divided into two groups receiving Ropivacaine with Dexmedetomidine (Group $\mathrm{RD}$ ) and Ropivacaine alone (Group R). (Group RD) showed higher statistical significant sedation scores compared to (Group R) throughout the study duration with $P$ value $<0.001$.

It also showed agreement with Saadawy et al. $^{\left({ }^{(28)} \text {, who }\right.}$ studied the effect of Dexmedetomidine on the characteristics of Bupivacaine in a caudal block in pediatrics. They received a caudal injection of Bupivacaine $(1 \mathrm{ml} / \mathrm{kg}$ ) (Group B) or the same dose of Bupivacaine mixed with Dexmedetomidine $(1 \mu \mathrm{g} / \mathrm{kg})$ (Group BD) during Sevoflurane anesthesia in infraumbilical surgeries. In their study, there was higher statistically significant sedation score in (Group D) than Control group $(\mathrm{P}<0.05)$. However, both groups of this study showed less sedation score than that of our study from the 1 st hour till the 6 hours postoperative. The sedation score in the (Group BD), it was $(2,2,1,1,0)$ and that of (Group B) was $(1,1,0,0,0)$ at $(1,2,3,4,6$ hours), respectively. That may be explained by their intraoperative monitoring of sedation using processed electroencephalogram (Bispectral Index Score).

In agreement with our study, El-Agamy et al. $^{\left({ }^{(29)} \text {, }\right.}$ explained in their study the effect of adding of Magnesium Sulfate (50mg) to caudal block in children scheduled for unilateral inguinal hernia repair or orchiopexy. The enrolled children were randomly allocated into one of two groups to receive either caudal
Bupivacaine $\quad(0.25 \%) \quad(1 \mathrm{ml} / \mathrm{kg})+$ Magnesium $\quad(\mathrm{BM}$ Group) or caudal Bupivacaine alone (B Group). The effect of caudal Magnesium Sulfate combined with Bupivacaine on the sedation score was significantly higher in the (Group BM) than in the (Group B) with (P $<0.001$ ) up to 15 minutes postoperative only. After 20 minutes postoperatively, the sedation score was the same in both groups (0) with no statistically significant difference.

Incontrast to our study, Sridhar et al. ${ }^{(15)}$, showed that there was no statistically significant difference with RSS by using different additives (Dexmedetomidine, Dexamethasone, Magnesium) in a dose of $(1 \mu \mathrm{g} / \mathrm{kg}$, $0.1 \mathrm{mg} / \mathrm{kg}$ and $50 \mathrm{mg}$ ), respectively. This might be explained by the use of a smaller volume of caudal injection in their study than in our study $(0.5 \mathrm{ml} / \mathrm{kg}) \&$ $(1 \mathrm{ml} / \mathrm{kg})$, respectively and/or the use of different general anaesthetics.

As regard postoperative agitation assessment using PAED score, our study revealed that patients in (Group D) and (Group M) showed lower statistically significant PEAD scores $(3.5,3,3)$ and $(4,3,3)$ than Control group $(6,5,4)$ at (5min, $15 \mathrm{~min}, 30$ minutes) postoperative, respectively with $\mathrm{P}$ value $<0.001$.

Our results came in agreement with Anand et $\boldsymbol{a l} .{ }^{(27)}$, their study concluded that children received Dexmedetomidine were more calm than those received Ropivacaine alone with statistically significant difference $(P<0,001)$, after Sevoflurane anesthesia.

In agreement with our study, Saadawy et al. ${ }^{(28)}$, showed that the incidence of agitation was lower by adding Dexmedetomidine to Bupivacaine to caudal block with $P$ value $<0.05$. The incidence of agitation in (Group BD) was $7 \%$ while in (Group B) was $27 \%$.

Also, our study was agreed with El-Agamy et al. ${ }^{(29)}$, their study showed that children in (Group BM) experienced less agitation than children in (Group B) with statistically significant difference $(\mathrm{P}$ value $<0.001)$ up to 10 minutes postoperative. After that, it was still less agitation in (Group BM), but with no statistically significant difference as evaluated by the PAED score.

As regard correlation test between pain, sedation and agitation in our study,

At 30 minutes postoperative, there was -ve correlation between pain and sedation with no statisitically significant difference $(P=0.206)$. There was less +ve correlation between pain and agitation with no statisitically significant difference $(P=0.142)$. There was -ve correlation between sedation and agitation with highly statistical significant difference $(\mathrm{P}<0.001)$.

At 60 minutes postoperative, there was -ve correlation between pain and sedation with statistically significant difference $(P=0.023)$. There was less +ve correlation between pain and agitation with no statistically significant difference $(\mathrm{P}=0.071)$.There was -ve correlation between sedation and agitation with statistically significant difference $(\mathrm{P}=0.028)$. 
In our study, the caudal block mainly used to relieve pain after Sevoflurane anesthesia with less incidence of emergence agitation. This confirmed by study of ElAgamyet al. ${ }^{(29)}$, who excluded the pain to cause AE by performing caudal block and the agitation associated with less sedation score.

Also, Singh et $\boldsymbol{a l} .^{(30)}$, who studied the effect of Isoflurane, Sevoflurane and Desflurane anesthesia on the incidence of emergence agitation in pediatric patients. Their study was on 75 pediatric patients, aged 4 months -7 years, scheduled for elective subumbilical surgery under general anesthesia. The study concluded that there was +ve correlation between agitation and pain scores. They detected that the agitation mostly associated with Sevoflurane anesthesia as the pain was adequately managed by pre-emptive rectal Paracetamol and caudal block. Also, not all high Flacc scores patients were agitatied especially Children who could easily evaluate and express their pain.

Regarding postoperative complications in our study, only one patient developed vomiting in Group M (5\%) postoperatively and two patients in Group D (10\%). Also, one patient in Group D (5\%) developed bradycardiaintraoperatively at the $60^{\text {th }}$ min after the administration of the block which was corrected with injection I.V (0.02mg) Atropine.

Our results came in agreement with the results of Khaled $\boldsymbol{e t} \boldsymbol{a l} .{ }^{(18)}$, showed in their study of efficacy and safety of Dexmedetomidine added to caudal Bupivacaine in pediatric major abdominal cancer surgery that the adding of Dexmedetomidine $(1 \mu \mathrm{g} / \mathrm{kg})$ to caudal Bupivacaine in pediatric achieved no recorded side effects.

It also showed agreement with Kim et $\boldsymbol{a l} .{ }^{(16)}$, their study of using Magnesium (50mg) as an adjuvant for children undergoing inguinal herniorrhaphy under general anesthesia with caudal block. Magnesium showed no patient experienced persistent paresthesia, bradycardia, hypotension, rash, pruritus, urinary retention requiring bladder catheterization, sedation resulting in a delayed discharge or wound problems.

In contrast to our study, Goyal et $\boldsymbol{a l} .{ }^{(22)}$, showed that the incidence of nausea and vomiting was higher in Group A (control group) (33\%) compared to Group B (DEX group) (16\%) unlike the incidence of vomiting in our study was higher in (Group D) (10\%) compared to (Group M) (5\%) and (Group C) (0\%) .

\section{CONCLUSION}

Administration of Dexmedetomidine as adjuvant with Bupivacaine enhances caudal block, prolongs duration of postoperative analgesia, reduces postoperative EA and provides preferred postoperative sedation in pediatric patient undergoing infraumbilical surgeries with minimum adverse effects compared to Magnesium Sulfate as adjuvant.

\section{REFERENCES}

1. Dalens B, Hasnaoui A (1989): Caudal anesthesia in pediatric surgery: Success rate and adverse effects in 750 consecutive patients. Anesth Analg., 68:83-9.

2. Morgan G, Mikhail M (1996): Pediatric anesthesia. In: Morgan GE, Mikhail MS, editors. Clinical Anesthesiology. 2nd ed. USA: Appleton and Lange, Pp. 726-42.

3. Gunter J, Dunn C, Bennie J, Pentecost D, Bower R, Ternberg J (1991): Optimum concentration of bupivacaine for combined caudal - General anesthesia in children. Anesthesiology, 75:57-61.

4. Silvani P, Camporesi A, Agostino M (2006): Caudal anesthesia in pediatrics. An update Minerva Anestesiol., 72:453-9.

5. Kalappa S, Sridhara R, Kumaraswamy S(2016):Dexmedetomidine as an Adjuvant to PreEmptive Caudal Epidural Ropivacaine for Lumbosacral Spine Surgeries. J Clin Diagn Res., 10: 22-24.

6. Swain A, Nag D, Sahu S, Samaddar D (2017): Adjuvants to local anesthetics: Current understanding and future trends. World J Clin Cases, 5(8):307-323.

7. Yousef G, Ibrahim T, Khder A (2014): Enhancement of ropivacaine caudal analgesia using dexamethasone or magnesium in children undergoing inguinal hernia repair. Anesth Essays Res., 8: 13-19.

8. Tong Y, Ren H, Ding X, Jin S, Chen Z, Li Q (2014): Analgesic effect and adverse events of dexmedetomidine as additive for pediatric caudal anesthesia: A metaanalysis. Paediatr Anaesth ., 24: 1224-30.

9. Wu X, Hang L, Wang H, Shao D, Xu Y, Cui W (2016): Intranasally administered adjunctive dexmedetomidine reduces perioperative anesthetic requirements in general anesthesia. Yonsei Med J., 57:998-1005.

10. Mason K, Lerman J (2011): Review article: dexmedetomidine in children: current knowledge and future applications. Anesth Analg., 113: 1129-42.

11. Smith I, Kranke P, Murat I (2011): Perioperative fasting in adults and children: Guidelines from the European society of anaesthesiology. European Journal of Anaesthesiology,28(8):556-569.

12. Brull R, MacFarlane A, Chan V (2015): Spinal, epidural, and caudal anesthesia. In: Miller R. D., editor. Miller's Anesthesia. Elsevier Health Sciences.

13. Armitage E(1986): Local anaesthetic techniques for prevention of postoperative pain. Br J Anaesth., 58: 790800.

14. Gupta S, Sharma R (2017): Comparison of analgesic efficacy of caudal dexmedetomidine versus caudal tramadol with ropivacaine in paediatric infraumbilical surgeries: A prospective, randomised, double-blinded clinical study. Indian J Anaesth., 61: 499-504.

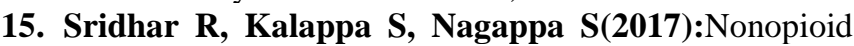
(Dexmedetomidine, Dexamethasone, Magnesium) Adjuvant to Ropivacaine Caudal Anesthesia in Pediatric Patients Undergoing Infraumbilical Surgeries: A Comparative Study. Anesth Essays Res., 11(3):636-641.

16. Kim J, Kim S, Lee J, Kang Y, Koo B (2014): Low-dose dexmedetomidine reduces emergence agitation after desflurane anesthesia in children undergoing strabismus surgery. Yonsei Med J., 55: 508-16. 
17. Park S, Shin S, Kim S (2017):Comparison of Dexmedetomidine and Fentanyl as an Adjuvant to Ropivacaine for Postoperative Epidural Analgesia in Pediatric Orthopedic Surgery. Yonsei Med J., 58(3):650657.

18. Khaled M, Ahmed H, Alieldin N (2014): Efficacy and Safety of Dexmedetomidine Added to Caudal Bupivacaine in Pediatric Major Abdominal Cancer Surgery. Pain Physician, 17: 393-400.

19. Mavuri G, Jain P, Chakraborty $S$, Mucherla $S$, Jadon A (2017): A randomized double-blinded comparison between dexmedetomidine and clonidine as an adjuvant to caudal ropivacaine in children for below umbilical surgery. J Clin Sci., 14:157-61.

20. Farrag W, Ibrahim A, Mostafa M, Kurkar A, Elderwy A (2015): Ketamine versus magnesium sulfate with caudal bupivacaine block in pediatric inguinoscrotal surgery: A prospective randomized observer-blinded study. Urol Ann., 7(3):325-329.

21. Tandale S, Vikram P, Prashant S, Kishor P, Rajkumar M, Kamal M (2017): Efficacy and safety of dexmedetomidine as an adjuvant to caudal levobupivacaine in paediatric patients." (2017). Pediatric Anesthesia and Critical Care Journal, 5(2):103-110.

22. Goyal V, Kubre J, Radhakrishnan $K$ (2016):Dexmedetomidine as an adjuvant to bupivacaine in caudal analgesia in children. Anesth Essays Res., 10:227-32.

23. El-Hennawy A, Abd-Elwahab A, Abd-Elmaksoud A, El-Ozairy H, Boulis S (2009): Addition of clonidine or dexmedetomidine to bupivacaine prolongs caudal analgesia in children. Br J Anaesth., 103: 268-74.
24. Jilani S, Qadir H, Saqib R (2018): Effect of adding magnesium sulphate to pediatric caudal bupivacaine, WJPMR., 4(7): 288-294.

25. Askar F, Ahmed J, Hassan M (2017): Effect of Adding Magnesium Sulphate to Pediatric Caudal Bupivacaine on Hemodynamics Parameters and Surgical Stress: Randomized Double-Blind Control Study. https://doi.org/10.24087/IAM.2017.1.8.262

26. Birbicer H, Doruk N, Cinel I, Atici S, Avlan D, Bilgin E (2007): Could adding magnesium as adjuvant to ropivacaine in caudal anesthesia improve postoperative pain control? PediatrSurg Int., 23:195-8.

27. Anand V, Kannan M, Thavamani A, Bridgit M(2011): Effect of dexmedetomidine on caudal ropivacaine in pediatric lower abdominal surgeries. Indian J Anaesth., 55: 340-6.

28. Saadawy I, Boker A, Elshahawy M, Almazrooa A, Melibary S, Abdellatif A(2009): Effect of dexmedetomidine on the characteristics of bupivacaine in a caudal block in pediatrics. Acta Anaesthesiol Scand., 53:251-6.

29. El-Agamy A, El-Kateb A, Mahran M (2015): Addition of magnesium sulfate to caudal block for preventing emergence agitation in sevoflurane-based anesthesia in children. Ain-Shams J Anaesthesiol., 8:217-22.

30. Singh R, Kharbanda M, Sood N, Mahajan V, Chatterji C (2012): Comparative evaluation of incidence of emergence agitation and post-operative recovery profile in paediatric patients after isoflurane, sevoflurane and desflurane anesthesia. Indian J Anaesth., 56(2):156-161. 